\title{
Impact of maternal income on the risk of gestational diabetes mellitus in primiparous women
}

Rönö, K.

2019-02

Rönö , K, Masalin , S , Kautiainen , H , Gissler , M , Raina, M , Eriksson , J G \& Laine , M K 2019 , ' Impact of maternal income on the risk of gestational diabetes mellitus in primiparous women ' , Diabetic Medicine , vol. 36 , no. 2 , pp. 214-220 . https://doi.org/10.1111/dme.13834

http://hdl.handle.net/10138/312863

https://doi.org/10.1111/dme.13834

acceptedVersion

Downloaded from Helda, University of Helsinki institutional repository.

This is an electronic reprint of the original article.

This reprint may differ from the original in pagination and typographic detail.

Please cite the original version. 
MRS KRISTIINA RÖNÖ (Orcid ID : 0000-0002-6344-1159)

Article type : Research Article

Diabetic Medicine

Article type: Research Article

Article number: 2018-00389

Copy editor: Maria Hale

Proofs to: kristiina.rono@helsinki.fi

Copyright: Diabetes UK

Author running head: K. Rönö et al.

Short title running head: Maternal income and risk of GDM

\section{Research Article: Pregnancy}

\section{Impact of maternal income on the risk of gestational}

\section{diabetes mellitus in primiparous women}

K. Rönö ${ }^{1,2}$, S. Masalin ${ }^{1,3}$, H. Kautiainen ${ }^{2,4}$, M. Gissler 5,6, M. Raina ${ }^{7,8}$, J. G. Eriksson 23,9 and M. K. Laine ${ }^{2,7}$

${ }^{1}$ Department of Obstetrics and Gynecology, University of Helsinki and Helsinki University Hospital,

${ }^{2}$ Folkhälsan Research Center and ${ }^{3}$ Department of General Practice and Primary Health Care, University of Helsinki and Helsinki University Hospital, Helsinki, ${ }^{4}$ Primary Health Care Unit, Kuopio University Hospital, Kuopio and ${ }^{5}$ National Institute for Health and Welfare, Helsinki, Finland, ${ }^{6}$ Department of This article has been accepted for publication and undergone full peer review but has not been through the copyediting, typesetting, pagination and proofreading process, which may lead to differences between this version and the Version of Record. Please cite this article as doi: 10.1111/dme.13834

This article is protected by copyright. All rights reserved. 
Neurobiology, Care Sciences and Society, Karolinska Institutet, Huddinge, Sweden, ${ }^{7}$ Vantaa Health Centre, Vantaa, and ${ }^{8}$ Apotti and ${ }^{9}$ Department of Chronic Disease Prevention, National Institute for Health and Welfare, Helsinki, Finland

Correspondence to: Kristiina Rönö.E-mail: kristiina.rono@helsinki.fi

\title{
What's new?
}

- Little is known about the simultaneous impact of maternal prepregnancy income and educational attainment on the risk of gestational diabetes mellitus (GDM).

- Both maternal prepregnancy annual taxable income and educational attainment show an inverse relationship with the risk of GDM.

- Women with low prepregnancy taxable income may need more support and guidance before and during pregnancy to reduce the risk of GDM.

\begin{abstract}
Aims Findings concerning the impact of socio-economic status on the risk of gestational diabetes mellitus (GDM) are inconclusive and little is known about the simultaneous impact of income and educational attainment on the risk of GDM. This study aims to assess the impact of maternal prepregnancy income in combination with traditional GDM risk factors on the incidence of GDM in primiparous women.
\end{abstract}

Methods This is an observational cohort study including 5962 Finnish women aged $\geq 20$ years from the city of Vantaa, Finland, who delivered for the first time between 2009 and 2015, excluding women with pre-existing diabetes mellitus. The Finnish Medical Birth Register, Finnish Tax Administration, Statistics Finland, Social Insurance Institution of Finland and This article is protected by copyright. All rights reserved. 
patient healthcare records provided data for the study. We divided the study population according to five maternal income levels and four educational attainment levels.

Results Incidence of GDM decreased with increasing income level in primiparous women $(P<0.001$ for linearity, adjusted for smoking, age, BMI and cohabiting status). In an adjusted two-way model, the relationship was significant for both income $(P=0.007)$ and education $(P=0.039)$, but there was no interaction between income and education $(P=0.52)$.

Conclusions There was an inverse relationship between both maternal prepregnancy taxable income and educational attainment, and the risk of GDM in primiparous Finnish women.

\section{$<$ H1 $>$ Introduction}

Gestational diabetes mellitus (GDM) is a common pregnancy disorder associated with adverse short- and long-term health implications for both the woman and her offspring [1-3]. The incidence of GDM has been increasing during past decades [4-6], making GDM a serious global health issue. Temporal increases in age and adiposity of pregnant women only partially explain the increase in GDM incidence [5].

Both in the general population and in pregnant women, obesity is associated with socioeconomic disadvantages $[7,8]$. Further, the association of socio-economic deprivation, low educational attainment and low income levels with an increased risk of Type 2 diabetes has been observed in several studies, as reviewed by Agardh and colleagues in 2011 [9], and in more recent publications $[10,11]$. When considering the relationship between socio-economic factors and GDM, some studies have observed an inverse association between socio-economic status $[4,12-14]$, educational attainment $[15,16]$ and the risk of GDM, although in other studies no such association has been detected $[17,18]$. No previous study has assessed the importance of personal maternal income, reported objectively as taxable income, simultaneously with traditional risk factors on risk of GDM in primiparous European women.

This article is protected by copyright. All rights reserved. 
In 2016, we initiated the Vantaa birth cohort study 2009-2015, a follow-up cohort study in the city of Vantaa, Finland, to assess the long-term consequences of gestational glucose intolerance on the health of women and their offspring. This study aims to assess the influence of maternal prepregnancy taxable income in addition to educational attainment and well-established traditional GDM risk factors, like maternal age and BMI, on the incidence of GDM in primiparous women.

\section{$<$ H1 $>$ Participants and methods}

The study includes all 5962 Finnish women (born in Finland with Finnish or Swedish as native language) aged $\geq 20$ years, from the city of Vantaa, who delivered for the first time between 1 January 2009 and 31 December 2015, and had no history of previously diagnosed diabetes mellitus.

Data on deliveries were collected from the Finnish Medical Birth Register (maintained by the National Institute for Health and Welfare in Finland), which receives information on all live births and stillbirths from 22 weeks or $500 \mathrm{~g}$ onwards from all Finnish maternity hospitals. From this source, we obtained data on maternal age at delivery, GDM, prepregnancy height and weight, number of previous pregnancies (miscarriages, induced abortions or ectopic pregnancies), use of any infertility treatment, smoking during pregnancy, cohabitation status, place of birth and native language [19]. Patient healthcare records were used to obtain complete information on GDM, height and weight. Data on diabetes mellitus treated with medication and diagnosed before pregnancy was obtained from the Finnish Social Insurance Institution which maintains a nationwide register of the right to reimbursable medication (The Social Insurance Institution of Finland; http://www.kela.fi/web/en/reimbursement-for-medicine-expences).

The diagnostic criteria used for diagnosis of GDM was one or more pathological glucose value in a standard 75-g 2-h oral glucose tolerance test (OGTT) with the following thresholds: fasting plasma glucose $\geq 5.3 \mathrm{mmol} / \mathrm{l}$, 1-h glucose $\geq 10.0 \mathrm{mmol} / \mathrm{l}$, and 2-h glucose $\geq 8.6 \mathrm{mmol} / \mathrm{l}$ [20] . Since 2008, the Finnish Current Care Guidelines for GDM have recommended screening for GDM This article is protected by copyright. All rights reserved. 
using an OGTT between 24 and 28 weeks of gestation for all pregnant women during their first pregnancy, except for those at low risk (i.e. nulliparous women aged $\leq 25$ years, with a BMI $<25$ $\mathrm{kg} / \mathrm{m}^{2}$ and without a first-degree family history of diabetes) [20]. Women at high risk (i.e. with a BMI $\geq 35 \mathrm{~kg} / \mathrm{m}^{2}$, glucosuria during pregnancy, first- or second-degree family history of Type 2 diabetes, use of oral corticosteroids or with polycystic ovary syndrome) should be tested for the first time at 12-16 weeks of gestation [20].

The Finnish Tax Administration provided data on maternal taxable income, including both earned and capital income. For prepregnancy annual income, we used each participant's mean taxable income for the year of conception and the two preceding years. The annual incomes were adjusted for the year 2017 value using a consumer price index (Statistics Finland; http://www.stat.fi/til/index_en.html). We divided the participants into five income level categories using centiles (levels I to $\mathrm{V}$, and percentiles 12.5, 37.5, 62.5 and 87.5) corresponding to grades containing $12.5,25,25,25$ and $12.5 \%$ of the total distribution, respectively. The respective annual incomes (€) were: 0-11120 for level I, > 11 120-22855 for level II, >22 855-29 940 for level III, > 29 940-40,190 for level IV, and > 40190 for level V. In 2016, the mean annual taxable income in Finland among women was €24 764, and the at-risk-of-poverty threshold for annual income per one adult was €14430 (Statistics Finland https://www.stat.fi/tup/suoluk/suoluk_tulot_en.html).

Statistics Finland provided data about the level and number of years of education. We divided education into the following four levels: basic education (level I) that comprises 9-10 years of school; upper secondary education or post-secondary non-tertiary education (level II) that comprises 11-14 years of school; bachelor's or equivalent education (level III) that comprises 15-16 years of school; and master's, doctoral or equivalent education (level IV) that comprises $\geq 17$ years of school.

This article is protected by copyright. All rights reserved. 


\section{$<\mathrm{H} 2>$ Ethical aspects}

The Ethics Committee of the Hospital District of Helsinki and Uusimaa (2 November 2015, Dnro $356 / 13 / 03 / 03 / 2015)$ and the health authority of the Vantaa city approved the study. National Institute for Health and Welfare, Statistics Finland and the Finnish Tax Administration gave their permission to use their register data in this study. According to the Ethics Committee of the Hospital District of Helsinki and Uusimaa, and the health authority of the city of Vantaa, the study participants do not need to provide the Statement of Informed Consent as this is an observational register-based study and the study participants were not contacted.

\section{$<\mathrm{H} 2>$ Statistical analysis}

Statistical significances for the unadjusted hypothesis of linearity across categories of income level and characteristics of the study participants were evaluated by using the CochranArmitage test [21], linear-by-linear association test and analysis of variance (ANOVA) with appropriate contrast. To further investigate the association between income levels and the incidence of GDM with 95\% confidence intervals (CI), logistic regression models were applied after adjusting for the following confounding factors: smoking, age, prepregnancy BMI and cohabiting status. The relationship between age and income was evaluated by use of penalized regression splines. Correlation coefficients with 95\% CI were calculated by using the Spearman method. The normality of the variables was tested by using the Shapiro-Wilk $W$ test. The Stata15.1 (StataCorp LP, College Station, TX, USA) statistical package was used for the analyses.

\section{$<$ H1 $>$ Results}

The mean (SD) age of the primiparous women at the time of delivery was 28.9 (4.9) years. The mean (SD) yearly taxable income was €26 864 (14 057) and the median (IQR) income was $€ 26529$ (18 270 to 34047$)$. Of the women, $13(0.2 \%)$ had no prepregnancy income. Table 1 shows the characteristics of the study participants according to their annual taxable income. This article is protected by copyright. All rights reserved. 
There was significant linearity between income level and the assessed prepregnancy characteristics of the participants except for prepregnancy BMI, which did not differ between women in different income level groups (Table 1).

The distribution of the yearly taxable income of the women and the relationship between age and income are shown in Fig. 1. The Spearman correlation coefficient between age and income was 0.59 (95\% CI 0.58 to 0.61$)$.

The incidence of GDM in the whole study population was $16.5 \%(n=988)$, and it decreased with increasing income, assessed both at different levels of income and on a continuous scale ( $P<0.001$ for linearity, adjusted for smoking, age, prepregnancy BMI and cohabiting) (Fig. 2). The odds ratio (OR) for GDM was 1.90 (95\% CI 1.78 to 2.30) for each 1 SD increase in BMI, after adjustment for age. Correspondingly, the OR for GDM for 1 SD increase in age was 1.35 (95\% CI 1.26 to 1.45$)$, after adjustment for BMI.

Figure 3 shows the relationship between incidence of GDM and annual taxable income level according to four educational attainment levels, adjusted for smoking, age, BMI and cohabiting. There was an inverse relationship between GDM and both income $(P=0.007)$ and education $(P=0.039)$, with no interaction between income and education $(P=0.52)$ (Fig. 3).

\section{$<$ H1 $>$ Discussion}

In this study cohort of primiparous women, the overall incidence of GDM was high at $16.5 \%$. The incidence of GDM showed an inverse association with both annual maternal prepregnancy taxable income and educational attainment. Income correlated strongly with maternal age. Furthermore, we observed a relationship between maternal prepregnancy taxable income level and several other maternal characteristics including height, prepregnancy weight, educational attainment, cohabiting and use of infertility treatments. The relationships between annual taxable income level, smoking and rate of prepregnancy obesity were inverse. Interestingly, This article is protected by copyright. All rights reserved. 
there was no difference between maternal prepregnancy BMI in the different income level groups. This study is the first one to explore the association between objectively reported maternal prepregnancy taxable income and risk of GDM - simultaneously taking into account other more traditional risk factors for GDM in European primiparous women.

During the study period, between the years 2009 and 2015 in Finland, the nationwide incidence of GDM, including both primiparous and multiparous women, increased from $9 \%$ to $16 \%$ [19]. Our study observation of a high GDM incidence is in line with nationwide data, as well as with previous findings from the same study cohort $[19,22]$. The comprehensive screening for GDM according to the Finnish Current Care Guidelines for GDM since 2008 probably explains our high incidence of GDM in these primiparous Finnish women [20].

In line with our findings, studies focusing on the relationship between socio-economic factors and risk of GDM have previously shown an association between socio-economic disadvantage and increased risk of developing GDM. In a large cohort study from Australia, maternal socioeconomic position, assessed according to the postcode of residence, was an important correlate for GDM [4]. Similarly, in a large Scottish cohort, the risk of GDM was highest among the socially most deprived women assessed with the Scottish Index of Multiple Deprivation of the area of residence [14]. Interestingly, however, in a cohort study from the United Kingdom, no association between socio-economic deprivation, similarly assessed according to the postcode of residence with a Townsend Material Deprivation Score, and rate of GDM was reported [17].

A Qatari study, including both primiparous and multiparous women, reported that a low monthly income increased the odds for GDM, although no association between educational attainment and GDM incidence was observed [13]. However, information on income in the Qatari study was self-reported, whereas in our study the income data was reported objectively as it was provided by the Tax Administrations register. Also, in a Canadian cohort study, women that belonged to the lowest quintile of taxable family income groups had a rate ratio of 2.48 for GDM compared with women in the highest family income group, after adjustments for This article is protected by copyright. All rights reserved. 
confounders [12]. We found a similar trend to the findings from the Qatari and Canadian study concerning the association of income and risk for GDM also in our Finnish cohort.

Partially in contrast to our findings, a Saudi Arabian [18] and a Chinese study showed no association between self-reported household income and GDM, whereas educational attainment in the latter study was inversely associated with the risk of GDM [16]. A Dutch study reported a similar inverse association between educational attainment and the risk of GDM. The finding was explained primarily by the higher rate of adiposity among women with lower educational attainment [15]. In the current study population, we also observed a protective effect of educational attainment on the development of GDM.

It is generally accepted that both an increase in maternal age and BMI are associated with an elevated risk of developing GDM $[14,23]$. Our findings are in line with the literature. However, the impact of increasing age on the risk of GDM seems to be modified by ethnicity; non-Hispanic whites and Hispanics being more adversely affected compared with other ethnicities [24].

Most studies focusing upon socio-economic status and GDM have traditionally used area of residence or educational attainment as indicators of socio-economic status $[4,14,17]$. We had the unique possibility to explore the effects of individual socio-economic status on the risk for developing GDM by using objective data on maternal annual taxable income as well as on individual educational attainment, taking both age and degree of adiposity into account.

The relationships between socio-economic status and various health outcomes have received large interest. Higher educational attainment has usually been associated with better health outcomes [25], whereas income level is inversely associated with the prevalence of several chronic non-communicable diseases, including diabetes [26]. The different socio-economic status indicators probably associate differently with health outcomes in general and during different phases of the life course [27]. Education is interpreted to reflect the knowledge-related assets of an individual and is mostly completed in young adulthood. Educational attainment, however, also partially determines future income. Income can be seen to have a direct effect on This article is protected by copyright. All rights reserved. 
material resources, and hence facilitate health-promoting factors like living environment or accessibility to health services [27]. It is challenging to assess, however, whether there is a causal effect of educational attainment or income on health [28]. In other words, it might also be possible that the association represents reverse causation between poor health and lower educational attainment and earnings [28,29]. Additionally, higher income [26] or higher socioeconomic status $[7,30]$ might reflect, at least to some extent, a healthier lifestyle in general. Similar relationships could be expected to influence weight control, physical activity, physical health and mental well-being during pregnancy and hence decrease the risk of GDM.

Our study has several strengths. The study cohort is comprehensive; during a period of 7 years, all Finnish women aged $\geq 20$ years from the city of Vantaa, the fourth biggest city in Finland, without previously diagnosed diabetes mellitus, and who delivered for the first time, were included in this study. The diagnosis of GDM is trustworthy because it is based on a standard 75-g 2-h OGTT and the diagnostic criteria for GDM remained the same during the whole study period. Further, annual maternal taxable income and educational attainment were not selfreported but based on objectively reported data obtained from the Finnish Tax Administration and Statistics Finland, respectively. We included only primiparous women to exclude the confounding effects of previous GDM or parity on the risk of GDM.

Our study also has some limitations. Because this is an observational register-based cohort study, we lacked data on some well-recognized risk factors for GDM such as family history of diabetes and gestational weight gain. We also lacked data on lifestyle-related factors including diet, physical activity and sleeping patterns. Possibly, some women have had undiagnosed diabetes mellitus before pregnancy and have therefore been misclassified as having GDM. Finally, the generalizability of our results globally might be limited, because the study participants were all Finnish women, mainly of European ancestry.

In conclusion, in our cohort of primiparous Finnish women aged $\geq 20$ years, the relationship between the level of both maternal income and education, and the risk of GDM was inverse.

This article is protected by copyright. All rights reserved. 


\section{Funding sources}

This study was funded by Research Foundation for Primary Health Care, Finland, The Hospital District of Helsinki and Uusimaa Finland, and Samfundet Folkhälsan, Finland. The funding sources had no role in the study design, collection, analysis or interpretation of the data, in the writing of the report or in the decision to submit the paper for publication.

\section{Competing interests}

None declared.

\section{Acknowledgements}

The Vantaa birth cohort study 2009-2015 was funded by Research Foundation for Primary Health Care, Finland, Hospital District of Helsinki and Uusimaa, Finland and Samfundet Folkhälsan, Finland. In addition, The Juho Vainio Foundation and the Helsinki University Doctoral School in Health Sciences supported the PhD study of the first author.

This article is protected by copyright. All rights reserved. 


\section{$<$ H1 $>$ References}

1 Damm P, Houshmand-Oeregaard A, Kelstrup L, Lauenborg J, Mathiesen ER, Clausen TD. Gestational diabetes mellitus and long-term consequences for mother and offspring: a view from Denmark. Diabetologia 2016; 59: 1396-1399.

2 American Diabetes Association. 2. Classification and diagnosis of diabetes. Standards of Medical Care in Diabetes-2017. Diabetes Care 2017; 40(Suppl 1): S11-S24.

3 Tobias DK, Stuart JJ, Li S, Chavarro J, Rimm EB, Rich-Edwards J et al. Association of history of gestational diabetes with long-term cardiovascular disease risk in a large prospective cohort of US women. JAMA Intern Med 2017; 177: 1735-1742.

4 Anna V, van der Ploeg HP, Cheung NW, Huxley RR, Bauman AE. Sociodemographic correlates of the increasing trend in prevalence of gestational diabetes mellitus in a large population of women between 1995 and 2005. Diabetes Care 2008; 31: 2288-2293.

5 Lavery JA, Friedman AM, Keyes KM, Wright JD, Ananth CV. Gestational diabetes in the United States: temporal changes in prevalence rates between 1979 and 2010. BJOG 2017; 124: 804-813.

Eades CE, Cameron DM, Evans JMM. Prevalence of gestational diabetes mellitus in Europe: a meta-analysis. Diabetes Res Clin Pract 2017; 129: 173-181.

7 Pigeyre M, Rousseaux J, Trouiller P, Dumont J, Goumidi L, Bonte D et al. How obesity relates to socio-economic status: identification of eating behavior mediators. Int J Obes 2016; 40: 1794-1801.

8 Heslehurst N, Ells LJ, Simpson H, Batterham A, Wilkinson J, Summerbell CD. Trends in maternal obesity incidence rates, demographic predictors, and health inequalities in 36 821 women over a 15-year period. BJOG 2007; 114: 187-194.

This article is protected by copyright. All rights reserved. 
Agardh E, Allebeck P, Hallqvist J, Moradi T, Sidorchuk A. Type 2 diabetes incidence and socio-economic position: a systematic review and meta-analysis. Int J Epidemiol 2011; 40: $804-818$.

Maier W, Holle R, Hunger M, Peters A, Meisinger C, Greiser KH et al. The impact of regional deprivation and individual socio-economic status on the prevalence of Type 2 diabetes in Germany. A pooled analysis of five population-based studies. Diabet Med 2013; 30: e78-e86. diabetes mellitus over a 3-year follow-up: results from a large Australian sample. Diabetes Res Clin Pract 2015; 108: 306-315. outcomes in a setting with universal access to essential health care services. CMAJ 2007; 177: 583-590.

Bener A, Saleh NM, Al-Hamaq A. Prevalence of gestational diabetes and associated maternal and neonatal complications in a fast-developing community: global comparisons. Int J Womens Health 2011; 3: 367-373.

14 Collier A, Abraham EC, Armstrong J, Godwin J, Monteath K, Lindsay R. Reported prevalence of gestational diabetes in Scotland: the relationship with obesity, age, socioeconomic status, smoking and macrosomia, and how many are we missing? J Diabetes Invest 2017; 8: 161-167. Bouthoorn SH, Silva LM, Murray SE, Steegers EAP, Jaddoe VWV, Moll H et al. Loweducated women have an increased risk of gestational diabetes mellitus: the Generation R Study. Acta Diabetol 2015; 52: 445-452. 
gestational diabetes mellitus among Chinese women. Diabet Med 2017; 34: 1421-1427.

17 Janghorbani M, Stenhouse EA, Jones RB, Millward BA. Is neighbourhood deprivation a risk factor for gestational diabetes mellitus? Diabet Med 2006; 23: 313-317.

Al-Rubeaan K, Al-Manaa HA, Khoja TA, Youssef AM, Al-Sharqawi AH, Siddiqui K et al. A community-based survey for different abnormal glucose metabolism among pregnant women in a random household study (SAUDI-DM). BMJ Open 2014; 4: e005906.

National Institute for Health and Welfare (THL). Perinatal Statistics - Parturients, Deliveries and Newborns 2016. Helsinki: THL, 2017.

Working group set up by the Finnish Medical Society Duodecim, the Medical Advisory Board of the Finnish Diabetes Association and the Finnish Gynecological Association. Gestational Diabetes: Current Care Guidelines. Available at www.kaypahoito.fi Last accessed 17 August 2018.

21 Armitage P. Tests for linear trends in proportions and frequencies. Biometrics 1955; 11: 375. in primiparous women-impact of age and adiposity: a register-based cohort study. Acta Obstet Gynecol Scand 2017; 40(Suppl 1): S11.

23 Savona-Ventura C, Vassallo J, Craus J, Anastasiou E, Jotic A, Lalic NM et al. Biological and biochemical characteristics of a Mediterranean population with gestational diabetes mellitus. J Perinat Med 2016; 44: 377-382.

24 Pu J, Zhao B, Wang EJ, Nimbal V, Osmundson S, Kunz L et al. Racial/ethnic differences in gestational diabetes prevalence and contribution of common risk factors. Paediatr Perinat Epidemiol 2015; 29: 436-443.

This article is protected by copyright. All rights reserved. 
25 Sasson I. Diverging trends in cause-specific mortality and life years lost by educational attainment: evidence from United States vital statistics data, 1990-2010. PLoS One 2016; 11: 00163412.

Blackwell DL, Lucas JW, Clarke TC. Summary health statistics for U.S. adults: national health interview survey, 2012. Vital Health Stat 2014; 260: 1-161.

27 Galobardes B, Lynch J, Smith GD. Measuring socioeconomic position in health research. Br Med Bull 2007; 81-82: 21-37.

28 Kawachi I, Adler NE, Dow WH. Money, schooling, and health: mechanisms and causal evidence. Ann NY Acad Sci 2010; 1186: 56-68.

29 Lynch JL, Hippel von PT. An education gradient in health, a health gradient in education, or a confounded gradient in both? Soc Sci Med 2016; 154: 18-27.

30 Mezuk B, Concha JB, Perrin P, Green T. Commentary: reconsidering the role of context in diabetes prevention. Ethn Dis 2017; 27: 63-68.

This article is protected by copyright. All rights reserved. 
FIGURE 1 Distribution of annual taxable income of all primiparous women and primiparous women with gestational diabetes mellitus (GDM), calculated as a percentage of the total study group. Dashed vertical lines indicate the cut-offs of five income level groups (I to V). The solid line shows the relationship between age and annual income among all women, evaluated by use of penalized regression splines with dashed lines representing 95\% confidence intervals.

Figure 2 Incidence of gestational diabetes mellitus (GDM), according to both the annual taxable income level and on a continuous scale (€1000), adjusted for smoking, age, BMI and cohabiting with logistic regression models. Annual income (€) was: level I, 0-11 120; level II, > 11 12022 855; level III > 22 855-29 940; level IV, > 29 940-40 190; and level V, > 40 190. Whiskers and shaded area represent $95 \%$ confidence intervals.

Figure 3 Relationship between incidence of gestational diabetes mellitus (GDM) and annual taxable income level according to four educational attainment levels, adjusted for smoking, age, BMI and cohabiting with a logistic regression model. Education was defined as: 9-10 years, basic education; 11-14 years, upper secondary education or post-secondary non-tertiary education; 15-16, bachelor's or equivalent education; and $\geq 17$ years, master's, doctoral or equivalent education. Annual income (€) was: level I, 0-11 120; level II, > 11 120-22 855; level III > 22 855-29 940; level IV, > 29 940-40 190; and level V, > 40 190. Whiskers show 95\% confidence intervals.

This article is protected by copyright. All rights reserved. 
Table 1 Characteristics of 5692 Finnish primiparous women, aged 20 years or older, and without previously diagnosed diabetes mellitus grouped according to annual taxable income level*

\begin{tabular}{|c|c|c|c|c|c|c|}
\hline & $\begin{array}{l}\mathrm{I} \\
(N=745)\end{array}$ & $\begin{array}{l}\text { II } \\
(N=149 \\
1)\end{array}$ & $\begin{array}{l}\text { III } \\
(N=149 \\
0)\end{array}$ & $\begin{array}{l}\text { IV } \\
(N=149 \\
1)\end{array}$ & $\begin{array}{l}\mathrm{V} \\
(N=745)\end{array}$ & $P$-value \\
\hline Age (years), mean (SD) & $24.4(4.4)$ & $26.6(4.2)$ & $29.0(4.1)$ & $31.2(3.8)$ & $33.2(3.6)$ & $<0.001$ \\
\hline Cohabiting, $n(\%)$ & $516(69)$ & $\begin{array}{l}1174 \\
(79)\end{array}$ & $\begin{array}{l}1210 \\
(81)\end{array}$ & $\begin{array}{l}1275 \\
(86)\end{array}$ & 649 (87) & $<0.001$ \\
\hline Smoker, $n(\%)$ & $259(35)$ & $326(22)$ & $227(15)$ & $143(10)$ & $50(7)$ & $<0.001$ \\
\hline $\begin{array}{l}\text { Years of schooling, mean } \\
\text { (SD) }\end{array}$ & $11.7(2.5)$ & $12.9(2.3)$ & $13.5(2.1)$ & $14.7(2.0)$ & $15.7(2.0)$ & $<0.001$ \\
\hline Height, (cm), mean (SD) & $165(6)$ & $165(6)$ & $166(6)$ & $166(6)$ & $167(6)$ & $<0.001$ \\
\hline $\begin{array}{l}\text { Prepregnancy BMI }\left(\mathrm{kg} / \mathrm{m}^{2}\right) \text {, } \\
\text { mean (SD) }\end{array}$ & $24.1(5.4)$ & $24.0(4.8)$ & $24.4(4.5)$ & $24.1(4.1)$ & $24.1(4.1)$ & 0.65 \\
\hline $\begin{array}{l}\text { Prepregnancy obesity (BMI } \\
\left.\geq 30 \mathrm{~kg} / \mathrm{m}^{2}\right), n(\%)\end{array}$ & $101(14)$ & $176(12)$ & $180(12)$ & $135(9)$ & $68(9)$ & $<0.001$ \\
\hline $\begin{array}{l}\text { Previous pregnancies, } n \\
(\%)\end{array}$ & & & & & & 0.003 \\
\hline None & $584(78)$ & $\begin{array}{l}1165 \\
(78)\end{array}$ & $\begin{array}{l}1207 \\
(81)\end{array}$ & $\begin{array}{l}1215 \\
(81)\end{array}$ & $603(81)$ & \\
\hline 1 & $98(13)$ & $225(15)$ & $205(14)$ & $210(14)$ & $97(13)$ & \\
\hline$\geq 2$ & $63(8)$ & $101(7)$ & $78(5)$ & $66(4)$ & $45(6)$ & \\
\hline Fertility treatment, $n(\%)$ & $21(3)$ & $70(5)$ & $114(8)$ & $209(14)$ & $129(17)$ & $<0.001$ \\
\hline Number of fetuses $\geq 2$ & $5(1)$ & $15(1)$ & $18(1)$ & $25(2)$ & $20(3)$ & $<0.001$ \\
\hline
\end{tabular}

*Annual income (€) was: level I, 0-11 120; level II, > 11 120-22 855; level III > 22 855-29 940; level IV, > 29 940-40 190; and level V, > 40190.

†For linearity

This article is protected by copyright. All rights reserved. 


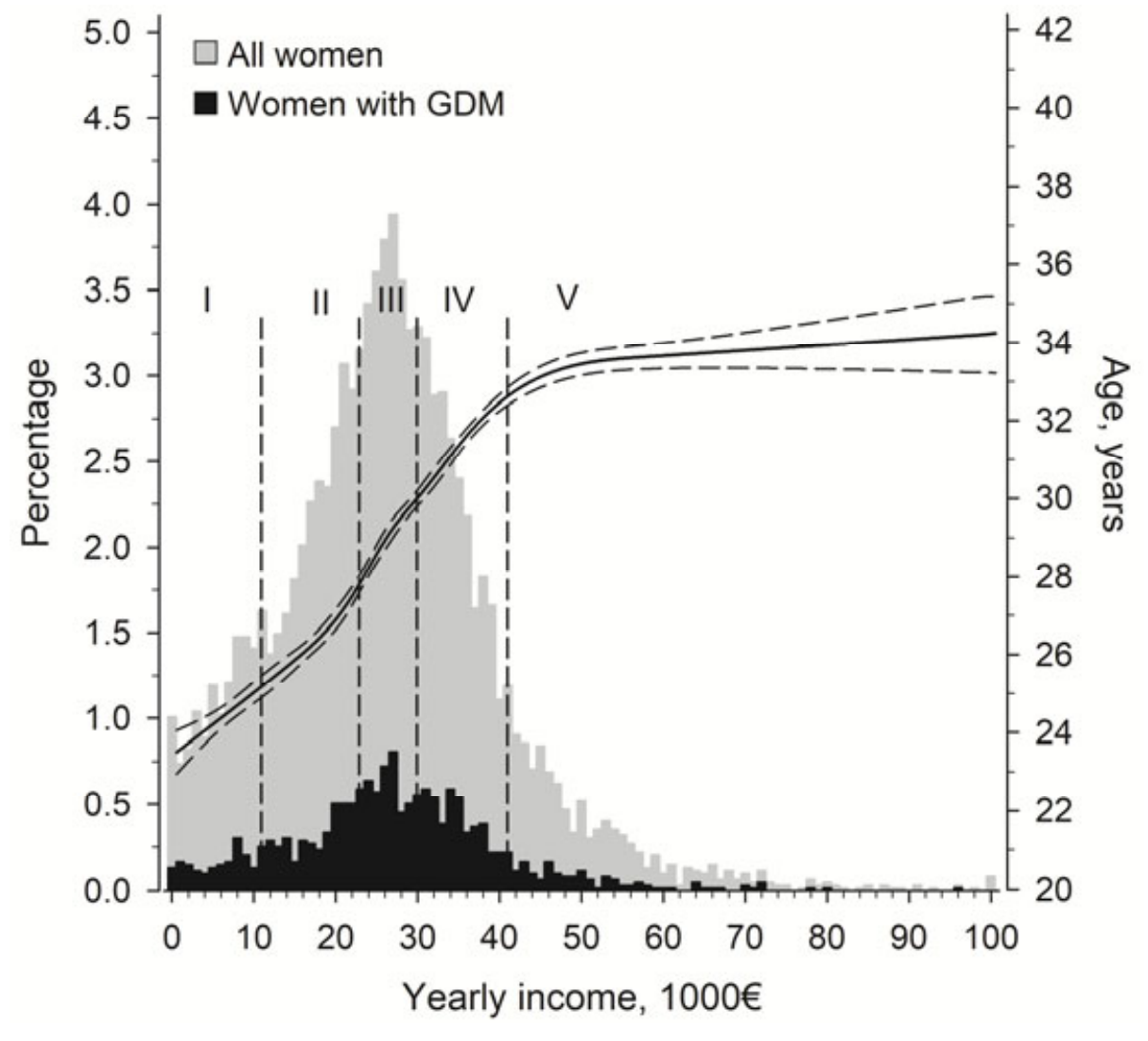

This article is protected by copyright. All rights reserved. 


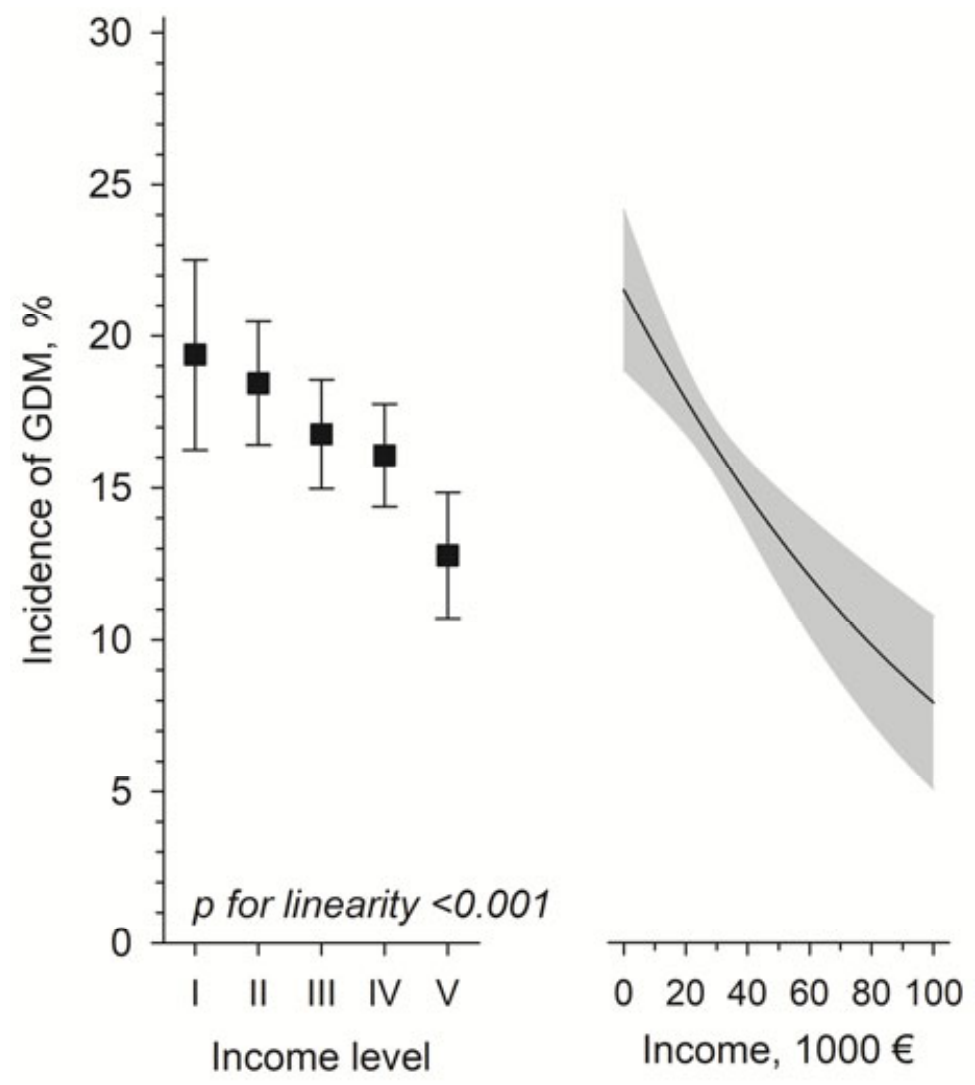

This article is protected by copyright. All rights reserved. 


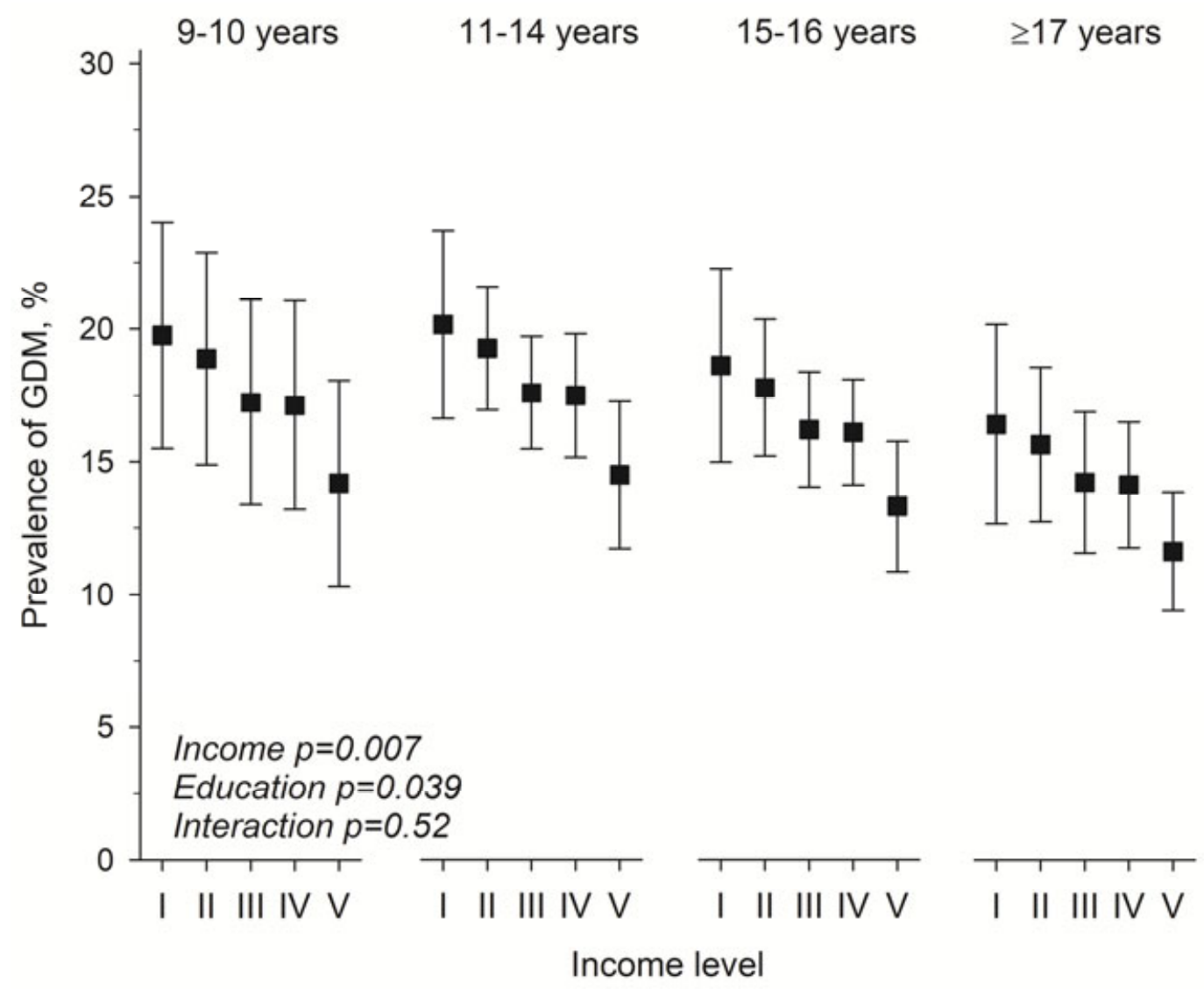

This article is protected by copyright. All rights reserved. 